\title{
Conceptual Bases of Use of Free Software in the Professional Training of Pre-Service Teacher of Mathematics, Physics and Computer Science
}

\author{
Vladyslav Ye. Velychko[ [0000-0001-9752-0907], Elena H. Fedorenko ${ }^{1[0000-0002-1897-874 X]}$ \\ and Darja A. Kassim ${ }^{2}$ \\ ${ }^{1}$ Donbas State Pedagogical University, 19, General Batiouk St., Sloviansk, 84116, Ukraine \\ \{vladislav.velichko, fedorenko.elena1209\}@gmail.com \\ ${ }^{2}$ Kryvyi Rih Metallurgical Institute of the National Metallurgical Academy of Ukraine, \\ 5, Stephana Tilhy St., Kryvyi Rih, 50006, Ukraine
}

\begin{abstract}
The development of education is associated primarily with the use of ICT. A significant experience is already gained in how to use educational computer systems while new forms and methods of learning based on modern information technology are being developed and used. In relation to free software, a period when the quantity should translate into quality and an indicator of such translation is development of the concept of the introduction of free software in educational activities of universities. The proposed concept, let's take Ukraine as an example, determines the main aim of introduction of free software in the training of pre-service of Mathematics, Physics and Computer Science; defines the objectives, measures, principles, the role and value of free software in the informatization process and results of its implementation.
\end{abstract}

Keywords: free software, teacher training, the concept of implementation.

\section{Introduction}

At all stages of development and functioning of the education process its formation was carried out using certain methods, techniques and tools. The peculiarity of the current stage of development of education is that in the arsenal of techniques and tools used in the preparation of pre-service specialists are both traditional (printed) and digital (electronic) materials. Ensuring open around the clock, access of students to electronic education today is one of the priorities of information science, education and culture of Ukraine. In this regard, the role and functions of teachers are significantly changing. It should be noted that a special role in this process is played by information and communication technologies as part of information-educational environment and include digital libraries, electronic educational resources, search engines and aggregation of information, which are based on the use of free software. 


\section{Results and Discussion}

The content of the educational process in higher educational pedagogical institutions is determined by effective programs used to train pre-service specialists in that particular university. The content of the educational training of a university is being approved by the Council of the pedagogical university, while the choice of content, methods, means and methods of work is determined by the individual departments and teachers with consideration of specifics of each educational direction. Software products which are used and guidelines developed by university teachers taking into account specifics of preparation of pre-service teachers create the basic component of fundamental training. In the modern paradigm of education it is necessary to develop educational standards which provide content of training upgrade as well as education of the younger generation on the principles of humanization, differentiation and integration.

The main objective of introducing of free software in the training of pre-service teacher of Mathematics, Physics and Computer Science lays in the formation of a new citizen of the information society, who feels comfortable in society, freely operates with information through new information technologies, respect the opinion of others and has his own opinion and knows how to deliver it, is capable of self-education, selfanalysis and has a motivation to obtain new knowledge and to self-improvement, while also understands the importance and inevitability of information education and society at large, giving preference to the latest information and educational technologies. In this case it refers to the use of free software for the transition to a new type of training of pre-service of Mathematics, Physics and Computer Science, which includes:

- creating optimal conditions for the acquirement of general and professional knowledge and skills and updating intellectual potential of pre-service teachers of Mathematics, Physics and Computer Science;

- promoting comprehensive and harmonious development of pre-service teacher of Mathematics, Physics and Computer Science as subjects of education process and information society;

- creating suitable conditions for the emotional and intellectual enrichment of preservice teacher of Mathematics, Physics and Computer Science as the basis of development and strengthening of political, social, economic, humanitarian, cultural and informational aspects of public life in the interest of the welfare of citizens, economic efficiency and country's growth.

Strategy aims related to the use of free software in preparation of pre-service teacher of Mathematics, Physics and Computer Science need to be determined in accordance with the benefits that its implementation provides to the educational process, which, in our opinion, are:

- free access to software and its source code;

- safety, reliability and stability of the software;

- overcoming of the digital divide;

- open standards independent from the developer;

- compliance with intellectual property rights, fight against piracy; 
- ability to fully adapt to suit individual needs;

- unlimited number of simultaneous installations on multiple computers in educational institutions and at home;

- the possibility of obtaining derivative software based on the original software platform and possibility to use it for private projects;

- possibility of software localization.

To achieve these objectives it is necessary to provide the following basic measures:

- analysis of didactic capabilities of free software through the procedure of examination and creating repositories of the recommended software provider;

- creating methodological, psychological and technological support for the use of free software in the preparation of pre-service teacher of Mathematics, Physics and Computer Science;

- analysis of readiness of subjects of the educational process for the use of free software;

- changing priorities as to the use of ICT in professional fields from studying certain software to studying technologies used to process information which in turn results in fundamentalization of the training of pre-service teacher of Mathematics, Physics and Computer Science (see [6]).

Introduction of free software in the process of professional training of pre-service of Mathematics, Physics and Informatics is not an aim in itself - it is first of all a way of enhancing performance based on changing priorities of study and use of ICT in education [4]. Currently, there is no single approach to the introduction of free software in the educational process; however, a considerable attention should be paid to implementing the following key principles:

Reform of educational processes. The main prerequisite for the successful implementation of free software is the understanding that it does not just mean analysis of the possibility of its use and the creation of guidelines to this process. First of all, it is about creating a new vision and new priorities in the use of ICT. The widespread of self-education must be supported and encouraged by modern information technologies. To use them it is necessary to have free access to the software, which access in turn is possible through the use of free software. Thus, on the one hand free software is an effective platform for modern paradigm of education, on the other - an example of open science, which is the basis for on open learning.

Motivation. The introduction of free software requires motivation to change the principles of the study and use of ICT in education. To include the free software in the list of software which is used in the preparation of pre-service teacher of Mathematics, Physics and Computer Science both internal and external motivations are required, which are based on the need for proper training of future professionals in information technology and internal vision of modern state of the information technology industry. Motivation will provide the initiatives to introduce free software, adapting them to today's challenges of education in preparing pre-service teacher of Mathematics, Physics and Computer Science. 
Strategic Initiatives. Taking into account the realities of austerity and financial resources as well as current needs of training of pre-service teachers of Mathematics, Physics and Computer Science, it is necessary to highlight the main priority funding projects which would be based on "protected" principle. Such projects should be characterized by a clear educational value, measured according to specific criteria.

Cooperation. It is necessary to introduce new forms of relationships between subjects of education process as well as cooperation within community of developers and users of free software. Firstly, university teachers must overcome the unwillingness of joint work with pre-service teacher of Mathematics, Physics and Computer Science towards the creation and use of electronic educational resources based on open standards and free software. On the other hand, cooperation in the use and development of free software can help the subjects of the educational process to successfully reform and speed up the implementation of free software.

The principle of open systems. Creation of information and educational environment which includes software and hardware, communication mechanisms, interfaces, data formats and protocols which are based on available and generally recognized standards ensuring cross-platform, collaboration and scale of applications and data. The software should be highly accessible to scientists as to educators. Information resources if possible should be maximally open and free to use.

The rule of law, legality, equality of all before the law. The rule of law is basically the position according to which people do not obey one another, but everyone obeys the rules which define among other things the form of direct relations with each other - through statuses or contracts. This rule of law applies to the degree of freedom of the free software called "copyleft" and to license agreements used in distribution of free software.

The freedom of intellectual and creative activity. Creativity is inherent to man in any field be it production, social communication, scientific activities and more. While performing its activities, society increasingly relies on achievement of intellectual work. In countries with high respect for science, culture and art - living standards are higher because achievements of intellectual activity dictate standard of production, culture and education, etc. Today, society must realize that the state should be interested in the development of science and education and, therefore, should support them. Such support may include direct government funding, certain tax benefits system to stimulate investment in research and development and so on. A striking example of innovative mental activity is the development and creation of software. In cases where the results of this activity are items of general use, has signs of openness and aimed at increasing and improving the heritage of humanity - then such smart, creative activity corresponds to human needs and can be used in education.

Social responsibility. The social phenomenon is a voluntary and conscious performance, use and compliance by subjects of social relations, regulations, social norms in regards to general doctrine of education development and to the implementation of specific measures of its implementation, including information education. The process of using free software must meet both legal and social norms, which is of particular importance to the educational process, particularly in education subsystem. Commitment to results of scientific, practical, creative and intellectual 
activity should be a significant factor in humanization of education and upbringing of socially responsible society members.

The main features of modern information society are: introduction of information to different spheres of life; concentration in the field of information and intellectual services of more than $40-50 \%$ of the population; development of general theory of information society; exponential growth of knowledge and accumulation of information; combining computer systems into a single information environment through means of communication; creating information in a digital code; extremely high development of production of technology and telecommunication technologies and means of communication requires a radical change in the field of education through information and adequate response to the demands of the information society.

According to the current Law of Ukraine on the National Informatization Program on 04.02 .1998 , in the current edition of 25.12.2015 was noted that informatization means a series of interrelated organizational, legal, political, socio-economic, scientific-technical, manufacturing processes aimed at creating conditions aiming to meet the information needs of citizens and society through the creation, development and use of information systems, networks, resources and information technology that are based on the use of modern computer and communications technology [7].

Computerization is driven by industry trends, including the informatization of education, by definition of Valerii Yu. Bykov, is a set of interrelated organizational, legal, socio-economic, scientific-methodological, scientific, technical, manufacturing and administrative processes aimed at meeting information, computing and telecommunication needs of subjects of the educational process. Informatization of education is associated with a wide introduction of methods and means of ICT in educational system, the creation on this basis of computer-based information and communication environment, filling this environment with electronic research, education and management of information resources enabling entities to carry out the educational process, provide access to environmental resources, to use its tools and services for solving various problems [1].

Let's define the role and place of free software in the informatization of education. The use of free software in preparation at the present level of informatization of educational activity plays a special role in preparation of pre-service teacher of Mathematics, Physics and Computer Science in the formation of a certain level of informative culture and intellectual development as well as in the formation of a scientific outlook, understanding the essence of practical orientation of informatics disciplines. The level of this training should equip pre-service teacher and make them to be able to create and implement new technologies theoretical framework of which might yet not be developed while they are still in their training.

One of the steps of informatization of educational process, improving the quality of training of pre-service teachers of Mathematics, Physics and Computer Science, enhancing teaching and learning and scientific and research activities, the disclosure of creative potential, the increasing role of self-education, according to Myroslav I. Zhaldak, is the creation and widespread adoption into teaching practice of computeroriented methodology of teaching based on the principles of progressive and not destructive embedding of ICT in active didactic systems, a harmonious combination of 
traditional and computer-oriented learning technologies, involving past achievements of pedagogical science of the past, improving and enhancing their achievements through the use of the achievements in development of computer technology and communications [8].

When looking at the methodological training system of Anatolii M. Pyshkalo using a systematic approach to the understanding of teaching methods, where all components of the educational process form a single system with defined internal connections, who defined methodical system of education as a set of five hierarchically related components: learning objectives, contents, methods, tools and organizational learning, which form a single integrated functional structure focused on achieving the learning objectives [8]. The described methodical system is a condition for sustainable development, stability and control of the educational process, which is impossible for teaching disciplines of informatics cycle and in view of the role and place of selfeducation in the educational process [3]. Similar arguments are used by Nataliia V. Morze an example of secondary school and Informatics as a school subject [2]. Considering the combination of methods, tools and organizational forms of traditional methodical teaching system all if which answer the question "how to teach?", scientists believe that this is the formation of a unified system of subsystems, called technology of education. Based on this structure of subsystem, they determine target, contents and technological components of methodical system of training [6].

Society shapes the social demand to preparation of pre-service teacher and defines objectives of any educational discipline. Thus, the modern information society is characterized by high development and use of information technology and advanced technologies which guarantee the production of information resources and access to these, processes of automatization of all sectors of production and management. While formulating the learning objectives of any disciplines, particularly fundamental, characteristics and requirements of the information society must be taken into account. Learning objectives, according to Yurii V. Tryus, is the initial condition for the creation of methodical system as the most specific and well-defined element of the system [6], that is, any modification of methodical system should, according to Morze, relate to the learning objectives [2] which describes the basic principle of improvement of methodical system - commitment.

The realization of principle of focus and aim is only possible through identification and development of specific components of methodical system, and vice versa development of content will determine the focus and aim of methodical system. Methodical system that uses free software as a means of teaching must take into account the basic principles and main trends of higher education and become basis to overcome the shortcomings of higher education and promote ways to overcome them, meet the new educational paradigm in terms of using ICTs to intensify the learning process. Methodical system of using free software should be based on a modular principle of development of curriculum subjects, to apply innovative educational technology of teaching, to widely use telecommunications and networking technologies, enable selfeducation and scientific and research activities, to use new methods and technology of teaching, to apply effective organizational and pedagogical forms of teaching. The result of the development of methodical system must be methodical complex suitable 
for use in any form of education as well as to be a component of the information and educational environment of an institution of higher education.

The main aims of the use of free software in the preparation of pre-service teacher of Mathematics, Physics and Computer Science are to demonstrate the essence of the scientific approach to the study of information processes and phenomena, the role of information technology in the development of scientific research and technological progress; to teach pre-service teachers techniques of how to use information technology in professional activities, methods of selection and analysis capabilities of the software; develop in students the ability to harmoniously use of ICT in education, to form skills of independent information processing and selecting appropriate technologies and tools.

The use of free software in the preparation of pre-service teacher of Mathematics, Physics and Computer Science should ensure formation of individuality of pre-service teachers, develop their intellectual abilities, analytical and synthetic thinking, information culture, mastering information technologies necessary for professional basic training and professional work, mastering techniques of information technology based on free software necessary to analyze social, economic, technical, manufacturing and information systems, search for optimal solutions to improve the efficiency of the systems, ability to choose the best ways to implement these solutions, processing and analysis of experimental results.

The results of the introduction of free software in the process of professional training of pre-service teacher of Mathematics, Physics and Computer Science, in our view are:

- development of information culture of a person, computer literacy (due to a change in priorities from studying of certain software to studying information technologies and their implementation);

- development of content, methods and means of education to international standards (due to lack of legal and financial restrictions on access to sophisticated achievements in information technology field);

- reducing the term and improving the quality of education at all levels of training of personnel (through enabling the use of information technologies anywhere and at a convenient time);

- integration of academic, research and production activities (through access to the source code of software and means to change it according to individual needs);

- improving the management of education activities (through the use of open standards for interoperability);

- opportunity to intensify the training of pre-service teachers of Mathematics, Physics and Computer Science (through fundamentalization of professional training).

An important factor of the concept of implementation of free software in the professional training of pre-service teacher of Mathematics, Physics and Computer Science is compliance with international and national standards. In view of this, special attention should be paid to standards of electronic documents that must conform to the principles of openness and accessibility. These standards include international standards for open file formats, such as OASIS Open Document Format ODF 1.0 (ISO / IEC 26300) and Office Open XML (ISO / IEC 29500). Unfortunately, the national 
standard GOST in this field does not exist, though, in our opinion, the existence of a national standard is needed to provide a framework of using open file formats.

The next step of standardization for Ukraine should be the definition of free software. This kind of standard was adopted in the Russian Federation (GOST R 54593-2011), which contains general provisions for free software and is based on international standard classification software (ISO / IEC TR 12182-2004) and processes lifecycle software (ISO / IEC 12207: 2016). Classification meets the standard of the types of programs and policy documents (GOST 19.101-77 operates in Ukraine) and the general requirements for policy documents (GOST 19.105-78 operates in Ukraine).

While defining goals, objectives, classification and criteria for free software, we determined that free software is created and used in order to create such market, where any service (copy, reproduction, modification, error correction, increasing the functionality, etc.) may be sold and bought in a competitive market by free-will contracting of both sides (supplier and buyer services) without appeal to a third party. This definition states the terms which define license purity of free software corresponding to known degrees of freedom. Based on the analysis in our study as to the specific tasks of free software use in Ukraine we include:

- providing import proprietary of components of information systems, reduction of dependence from monopolies, i.e. freedom of action on Ukrainian information space;

- stimulate the development of national (domestic) industry of development of software for computer systems;

- expanding opportunities for participation in development works and services for state and municipal needs and the needs of the private business sector by providing additional investment in domestic producer;

- ensuring a high level of technological independence;

- reducing number of violations related to the legal protection of software for computer systems.

Drawing from these tasks, we believe that infrastructure of development and use of free software should include:

- isolated environment of software packages (means of obtaining the source code of software binary files are directly loaded onto computer systems) and other means of collective development;

- single repository of software for computer systems and source code for various hardware and software platforms including ready distributions of basic software application and standard software solutions;

- control system of software for computer systems, providing records and the right to use and reuse of software and their components;

- infrastructure support for users and developers;

- infrastructure implementation (application) of open standards and specifications, including automation assess of compliance with standards (specifications). 
Expected outcomes of introduction of free software are, above all, in the transformation of educational technology, due to:

- transition from delivering already formed knowledge and its memorization to independent information search and constructing their own knowledge;

- joint training activities of pre-service teacher in different educational situations and simulating future professional situations;

- providing educational material in a nonlinear format;

- opportunity to study independently according to individual path and in his optimum pace;

- modeling of world processes and events during educational activities ;

- revitalization of intellectual and emotional processes of perception, understanding, comprehension and interpretation of educational material through the integration of verbal, graphic and audiovisual information;

- satisfactory qualification of teachers and pre-service teachers in the field of information and communication technology (equal to the level of International / European Computer Driving License);

- satisfactory qualification of graduated in the field of information and communication technology;

- quality access for teachers and students to their own internal and external e-learning and teaching resources ;

- quality access for teachers and senior students to scientific electronic resources;

- automated control of their own activities for teachers and students ;

- use of wholly licensed software.

The result of preparing of pre-service teacher of Mathematics, Physics and Computer Science to be able to use free software in their own training will serve as their willingness to use free software in their own teaching careers.

\section{Conclusions}

The proposed conceptual basis is an open system enabled by its interaction with the environment (social order, standard of professional education, etc.) and integration of knowledge of pre-service teacher of Mathematics, Physics and Computer Science in such scientific fields as philosophy, psychology, pedagogy, theory and methods of teaching mathematics, theory and methods of teaching physics; theory and methods of teaching information technology as well as fundamental disciplines in the field of preparation of Mathematics, Physics and Computer Science. Conceptual framework can be supplemented and extended depending on the conditions and characteristics of the operation and can be used in the preparation of preservice teachers to design the educational process from various disciplines based on their specifics.

The proposed conceptual basis is an integrated system. Each structural element of the proposed principles of the system is its subsystem. This concept of integrity is ensured through: 
- the presence of such properties and qualities which are not inherent in its structural elements;

- coherence and mutual dependence of all structural elements of conceptual principles as structural and logical and functional links between them.

Structural and logical connection provided by relationships and relationships of structural elements with each other and with over-system (social demand, state educational standard of higher education in "Pedagogical Education"). Functional connections of structural elements are defined by concept of efficacy provide by the aggregate of the basic principles and conceptual provisions.

\section{References}

1. Bykov, V.Yu.: Suchasni zavdannia informatyzatsii osvity (Modern tasks of informatization of education). Information technology and learning tools. 15(1) (2010)

2. Morze, N.V.: Osnovy metodychnoi pidhotovky vchytelia informatyky (Basics of methodical training of informatics' teachers). Kurs, Kyiv (2003)

3. Semerikov, S.O., Teplytskyi, I.O.: Vilne prohramne zabezpechennia yak faktor stabilizatsii vuzivskykh kursiv informatyky (Free Software as a factor in the stabilization of university computer science courses). In: Proceedings of Ukrainian scientific and practical conference on Information technologies in education, MSPU, Melitopol, 24-26 May 2006, pp. 55-56 (2006)

4. Semerikov, S.O., Teplytskyi, I.O.: Z dosvidu vykorystannia Vilnoho prohramnoho zabezpechennia u pidhotovtsi maibutnoho vchytelia (The experience of the use of Free Software in preparing future teachers). Ridna shkola. 5, 40-41 (2003)

5. Semerikov, S.O.: Fundamentalizatsiia navchannia informatychnykh dystsyplin u vyshchii shkoli (Fundamentalization of Computer Science teaching at the high educational institutions). Mineral, Kryvyi Rih (2009)

6. Tryus, Yu.V.: Kompiuterno-oriientovani metodychni systemy navchannia matematychnykh dystsyplin u VNZ: problemy, stan i perspektyvy (Computer-oriented methodical systems of teaching mathematical disciplines in higher educational institutions: problems, state and prospects). Naukovyi chasopys NPU imeni M. P. Drahomanova, Seriia 2: Kompiuterno-oriientovani systemy navchannia. 9, 16-29 (2010)

7. Verkhovna Rada Ukrainy: Zakon Ukrayiny Pro Natsionalnu prohramu informatyzatsii (Law of Ukraine: On the National Informatization Program). Zakonodavstvo Ukrainy. http://zakon3.rada.gov.ua/laws/show/74/98-\%D0\%B2\%D1\%80 (1998). Accessed 25 Dec 2017

8. Zhaldak, M.I.: Pedahohichnyi potentsial kompiuterno-oriientovanykh system navchannia matematyky (Pedagogical potential of computer-oriented systems of teaching mathematics). Kompiuterno-oriientovani systemy navchannia. 7, 3-16 (2003) 